JOVENS E VELHOS: REPRESENTAÇÕES

SOCIAIS CRUZADAS - O CONTRIBUTO

DA ANIMAÇÃO SOCIOEDUCATIVA NA

RECONFIGURAÇÃO DAS REPRESENTAÇÕES

SOCIAIS ENTRE JOVENS E VELHOS: O

PROJETO 'ENTRE NÓS: OS LIVROS'

\title{
António Leal1
}

resumo

Os jovens representam os idosos e a velhice com atributos e características negativas, associando a este momento do ciclo de vida um conjunto vasto de perdas físicas, cognitivas e sociais. Todavia os velhos não se reveem nessas imagens, não se representam nem se caracterizam negativamente.

Por outro lado, as pessoas idosas ou velhas representam os jovens com atributos e características muito positivas associadas particularmente à jovialidade deste ciclo de vida. Mas acrescentam a estas representações algumas características negativas, sobretudo relacionadas com determinados aspetos comportamentais.

A função social da animação socioeducativa é considerar os anciãos capazes de participar e intervir na vida comunitária. Interessa particu-

1 Especialista em Trabalho Social e Orientação. Professor adjunto do Instituto Politécnico de Coimbra - Escola Superior de Educação. Fundador e Presidente da Direção do Instituto Humanus - Instituto para a Promoção e Desenvolvimento da Educação ao Longo da Vida. E-mail: antonio@esec.pt. 
larmente nos processos de participação que estimulem os processos de desenvolvimento social e cultural. A participação intergeracional é sem dúvida um pilar em todo este processo, a partir do qual se definem as práticas de animação sociocultural.

Procuraremos neste artigo responder a algumas questões que nos ajudarão a compreender como as relações intergeracionais contínuas influenciam a perceção e as representações sociais que os jovens fazem dos idosos e vice-versa.

Este trabalho baseia-se nos dados preliminares recolhidos no âmbito de uma investigação-ação em desenvolvimento, pelo que as suas considerações não são de forma alguma conclusivas.

palavras-chave

Velhice. Representações Sociais. Intergeracionalidade. Interações Sociais. Animação Socioeducativa.

\section{Introdução: representações sociais entre jovens e velhos}

Ao falarmos de representações sociais entre jovens e velhos, abordamos as imagens que cada um destes grupos sociais constrói sobre si e sobre o 'outro'.

Segundo Moscovici (1981, p. 181, grifos nossos), as representações sociais são "Um conjunto de conceitos, proposições e explicações criado na vida quotidiana no decurso da comunicação interindividual. São o equivalente, na nossa sociedade, dos mitos e sistemas de crenças das sociedades tradicionais, podem ainda ser vistas como a versão contemporânea do senso comum", tendo como principal função tornar familiar o não-familiar. É sobretudo a forma como o senso comum expressa seu pensamento (JODELET, 1993).

Mais do que uma resposta individual a um determinado estímulo social, as representações sociais são a maneira como os grupos sociais constroem e organizam diferentes significados dos estímulos do meio social e as possibilidades de respostas que podem acompanhar esses estímulos. Têm por isso uma natureza social, pois são construções simbólicas da realidade, construídas nas e a partir das interações sociais, constituindo-se como aspetos socialmente significativos (JODELET, 1993; VALA, 1993; 2000).

Porém, apesar de serem compartilhadas pelos grupos sociais, não são homogéneas para a sociedade. São convencionais e prescritas e ao mesmo 
tempo dinâmicas, podendo variar em função do grupo, do contexto cultural e do contexto histórico.

As representações sociais são forma e conteúdo, simultaneamente, adquiridas por um processo de objetivação ou por ancoragem.

Para Moscovici (1981, p. 110-112), o processo de objetivação "[...] faz com que se torne real um esquema conceptual, com que se dê a uma imagem uma contrapartida material". Nesse caso, a objetivação consiste em dar substância, forma e solidez a um determinado conceito. Dá-se a construção formal de um conhecimento ao nível de senso comum. O abstrato torna-se a este nível concreto através da expressão de imagens, atributos e metáforas.

O processo de ancoragem envolve, para Moscovici (1981, p. 110-112), a integração cognitiva do objeto representado no sistema de pensamento preexistente, a representação social por ancoragem situa-se no seguimento da objetivação que se evidencia como referência, imagem de partida.

As pessoas que não se consideram velhas, sobretudo os jovens, associam aos 'mais velhos' e à velhice características negativas, associando a este momento do ciclo de vida, um conjunto vasto de perdas significativamente condicionantes do bem-estar físico e social, mas principalmente, de inutilidade para a sociedade. Representam os 'mais velhos' e a velhice com debilidade física; debilidade cognitiva; desatualizados e desadaptados aos tempos da modernidade; vivendo, muitos, das memórias passadas; inutilidade social e isolamento social.

Por seu lado, as pessoas idosas ou velhas representam os jovens com características mais positivas, associadas à jovialidade desse ciclo de vida. Enfatizam, ainda, o facto de estes beneficiarem, hoje, de mais acesso a meios e recursos de desenvolvimento, bem como de maiores e melhores oportunidades sociais. Mas acrescentam-lhes características negativas, sobretudo relacionadas com aspetos comportamentais formais, associando principalmente a estes, uma educação permissiva e alguma imaturidade social.

Não obstante, a perceção e imagem que constroem e partilham acerca dos jovens de hoje ser francamente positiva, essa imagem, carregada de significados positivos, não gera nos mais velhos um sentimento de nostalgia, nem desperta o desejo de querer voltar atrás no tempo. Pelo contrário, valorizam as suas trajetórias de vida, as suas experiências e conquistas alcançadas. Gostam de ser o que são, projetando e objetivando a velhice e todas as características negativas a ela associadas, ao 'outro mais velho', pertencente a um outro grupo etário distinto daquele a que pertence. Porém, invejam a condição e a destreza física dos jovens. Pois desejam ser tudo o que são hoje, com melhor condição física, pois sentem-se presos a um corpo que os condiciona, os limita 
significativamente na capacidade de concretização dos seus desejos, vontades e aspirações (LEAL, 2015).

As representações sociais descritas anteriormente resultam de um exercício solicitado a um grupo de estudantes da Licenciatura em Animação Socioeducativa e a um grupo estudantes do programa 'Escola de Educação Sénior', de uma instituição pública de Ensino superior em Portugal, participantes num projeto de animação socioeducativa, intitulado Entre Nós: os Livros, do qual falaremos mais à frente.

Estamos certos de que o facto deste exercício acontecer numa altura e num contexto em que ambos os grupos estão ou estiveram, em algum momento, em interação direta ou indireta, poderá ter exercido alguma influência no processo de objetivação dessas imagens, apesar de terem procurado ancorar as ideias e imagens pré-existentes. Todavia, elas não se distanciam muito das representações sociais que ambos os tipos de grupos constroem, e já apresentados noutros estudos no âmbito da sociologia, da antropologia ou da psicologia social (SANTOS; TURA; ARRUDA, 2011; SILVA, 2011; SILVA, 2006; DEBERT, 2004; MARTINS; RODRIGUES, 2004; BEAUVOIR, 1990; HADDAD, 1986).

\subsection{Relações e interações entre os jovens e os velhos}

As relações entre jovens e velhos podem-se caracterizar por diferentes tipos: 1) Restrita ao contexto familiar; 2) Restrita ao contexto académico ou profissional e 3) Pontual ou inexistente.

As duas primeiras situações resumem-se às interações sociais entre os jovens e os velhos no contexto familiar, com os seus avós ou outros familiares de maior idade, ou ainda no contexto académico ou profissional em que as interações se dão em nível das relações de autoridade e de poder, em que os 'mais velhos' representam e exercem o domínio do capital cultural e económico, representado tanto pelo professor como pelo chefe ou patrão sexagenário. $\mathrm{Na}$ última tipologia, as interações são de carácter pontual e mínimo, pois dão-se com o empregado do café que frequenta pontualmente, na repartição pública no momento em que necessita de tratar de um assunto legal, nos transportes públicos, etc.

Se as interações sociais entre diferentes gerações constituíram desde sempre o pilar da continuidade e preservação das sociedades e das suas instituições sociais e culturais, independentemente dos contextos culturais, na verdade, a separação das gerações, em contextos sociais e espaciais restritos, 
como os lares e centros de dia, contribui significativamente para o enfraquecimento das interações sociais entre diferentes gerações.

A baixa interação social entre gerações e o consequente afastamento origina também alterações nas representações sociais que cada grupo tem relativamente ao 'outro'. Quanto maior o afastamento social, maior o desconhecimento entre ambos os grupos e maior a probabilidade de a comunicação, no seio dos grupos, se orientar e guiar a partir de imagens estereotipadas negativas.

É nesse sentido que acreditamos que as relações intergeracionais contínuas, e duradouras, podem influenciar a perceção e as representações sociais que os jovens fazem dos 'mais velhos' e vice-versa.

A criação do programa 'Escola de Educação Sénior' no seio da Escola Superior de Educação de Coimbra (ESEC) veio enriquecer o ambiente:

[.. . ] contribuindo para a construção de um contexto socioeducativo caracterizado por uma maior diversidade de gerações em processos de aprendizagem, pela partilha de espaços de formação, de espaços de socialização comuns, de professores, de recursos, etc. Os estudantes seniores, alargaram a comunidade educativa 'esequiana2', transformaram a paisagem humana da Escola. [.. .]. Já não é estranho cruzarem-se com seniores a subir ou a descer as escadas rumo às salas de aulas ou de saída das aulas, [. . .] observar um ou outro grupo de estudantes seniores entre os vários grupos de estudantes das licenciaturas que socializam nos claustros ou no pátio e, não raras vezes, grupos mistos, de seniores e não seniores, em momentos de grande convivialidade" (LEAL, 2015, p. 85; SALGADO; LEAL, 2015, p. 105, grifos do autor).

O ambiente intergeracional proporcionado é de facto um dos aspetos mais significativos valorizados pelos estudantes que frequentam regularmente a Escola de Educação Sénior de Coimbra (LEAL, 2015, p. 85):

Acredito que este género de projecto neste tipo de instituição, com jovens, pode ajudar os jovens a mudar de atitude face aos mais idosos, pois eles vêm-nos a andar por aqui, com algum dinamismo, independentes, etc. (Alexandrina, 65 anos, Administrativa).

Agora em relação ao ambiente da escola, foi melhor do eu pensava. Porque eu tive sempre uma boa relação com os mais novos, com a juventude, com as amigas das minhas filhas, que conheço desde miúdas. Mas aqui não, fizemos trabalhos em conjunto... Depois a convivência com todos é muito boa, não há tanto formalismo. Até com os professores. (Beatriz Madeira, 65 anos, Médica).

2 Expressão que estudantes e professores utilizam frequentemente para designarem a ESEC como comunidade. 
[...] nós temos um colega que está ausente, que tinha as disciplinas com os jovens [50 Plus] e ele falava muito disso e notava que havia uma grande proximidade entre eles [os jovens e o colega ausente], era tu cá tu lá... Na Figueira da Foz [Buarcos] foi uma belíssima jornada, houve uma grande aproximação, eles [jovens da Licenciatura em ASE] ouviam-nos muito. [Állvaro Ribeiro, 75 anos, Bancário].

Esta experiência relacional entre gerações distantes caracteriza-se por ser uma interação de grande impacto, na perceção e avaliação que cada grupo faz do 'outro', uma vez que estamos perante uma interação social entre gerações mais regular, com maior continuidade no tempo (LEAL, 2015; SALGADO; LEAL, 2015), aumentando as possibilidades de gerar um maior espírito de convivialidade e sociabilidade, proporcionando um maior conhecimento, solidariedade e partilha entre as diferentes gerações em presença.

A dinâmica proporcionada fá-los sentir significativamente valorizados, despertando neles um sentido de utilidade ao serem frequentemente solicitados por estudantes e por professores. Descobrem neste ambiente intergeracional um lugar de pertença, novos papéis: o de estudante, o de colega mais velho, o de sábios quando são chamados a participar e a partilhar aprendizagens, perceções e análises adquiridas a partir das experiências vividas ao longo dos seus muitos anos de vida, "[...] devolvendo-lhes a capacidade crítica e a liberdade de expressão" (OLIVEIRA; OLIVEIRA, 2002, p. 16). Por um lado, o programa contribui para uma ressocialização dos adultos idosos e, por outro, de socialização das gerações mais jovens com os 'mais velhos' (LEAL, 2015, p. 86).

A inserção dos adultos 'mais velhos' - seniores, na comunidade universitária, aumenta efetivamente a probabilidade de interações entre diferentes gerações. No entanto, não sendo espontâneas, é possível que estas sejam provocadas e fomentadas através de estratégias de intervenção de animação socioeducativa. Estas requerem ações ambiciosas em termos didáticos e pedagógicos, exigindo uma avaliação e atualização contínuas (LEAL, 2015; SALGADO; LEAL, 2015).

\subsection{Papel e função da animação socioeducativa na promoção e normalização das relações intergeracionais}

A função social da animação socioeducativa neste âmbito é consi derar os anciãos capazes de participar e intervir na vida comunitária. 
A participação intergeracional é sem dúvida um pilar fundamental em todo este processo, a partir do qual se definem as práticas de animação sociocultural, apresentando-se como algo normal e contínuo. Importa por isso à animação sociocultural, independentemente da sua modalidade (cultural, social ou educativa), exercer uma função de normalização das relações entre as diferentes gerações em presença na sociedade.

Interessa particularmente para o cumprimento desta função de normalização e nos processos de participação a empreender, criar espaços para a comunicação dos grupos e das pessoas, que estimulem os diferentes agentes a empreender processos de desenvolvimento social e cultural, numa clara oposição a qualquer tendência de separação e consequentemente de segregação social e etária.

\section{Estratégias de animação socioeducativa}

Neste sentido, e no âmbito do Programa Escola de Educação Sénior de Coimbra, a animação socioeducativa tem tido um papel relevante no desenvolvimento de processos intergeracionais relevantes, contribuindo para a aproximação entre as diferentes gerações, sobretudo para a mudança das representações sociais que ambos os grupos (jovens e velhos) têm um do 'outro'.

Têm sido várias as ações dinamizadas, desde o início do programa, que são levadas a cabo em conjunto entre os estudantes 'mais velhos', alunos da Escola de Educação Sénior e os estudantes juniores de diferentes licenciaturas da ESEC. Uma delas é o Programa 50 Plus, que permite que estudantes da Escola Sénior frequentem Unidades curriculares das licenciaturas, participando principalmente nas dinâmicas e nos trabalhos realizados na sala de aula. Outras ações são constituídas por atividades ou projetos de curta duração, criados e dinamizados em equipas intergeracionais. É organizado também todo um conjunto de atividades, como seminários e oficinas, destinado aos estudantes 'mais velhos' e estudantes das licenciaturas, em particular os de Animação Socioeducativa, como é exemplo a 'Semana Aberta', cujas temáticas e convidados servem os dois públicos ${ }^{3}$.

3 Outras há em que os estudantes 'mais velhos' (seniores) são convidados a participar ativamente, como acontece com a participação na semana de formação residencial realizada no âmbito da unidade curricular de Organização e Animação de Campos e Colónias de Férias, do curso de licenciatura em Animação Socioeducativa, em que os estudantes da Escola Sénior são convidados a participar integralmente num dia de formação prática, das $10 \mathrm{h00}$ da manhã às 23h00, num centro de férias nas proximidades da cidade de Coimbra, integrando os diferentes grupos que se vão constituindo durante o dia e participando igualmente em todos os desafios propostos. 
Apesar da existência de um número diversificado de ações que fomentam e estimulam o intercâmbio e as interações sociais intergeracionais, a maioria dessas ações são de curta duração. Porém, como já afirmámos, elas têm sido suficientes para gerar imagens positivas do 'outro'.

No entanto, acreditamos que a possibilidade dos juniores e os adultos 'mais velhos' estabelecerem uma relação mais duradoura, assente em interesses e objetivos comuns, ou motivada por uma missão comum, poderá provocar um rápido afastamento das representações sociais até aí existentes sobre o 'outro' a partir da ancoragem a objetivações pré-existentes. Ou seja, a experiência vivida permitirá reter e selecionar outras informações (aspetos e atributos), dando origem a novos conteúdos que, por sua vez, darão forma a novas imagens, a novos esquemas mentais sobre o 'outro'. Ao reformular-se a objetivação, surgirão novas representações socialmente mais significativas, pelo menos entre estes grupos especificamente.

Foi com o propósito de perceber se uma ação com as características definidas anteriormente poderia gerar o efeito descrito, que se desenvolveu o Projeto de intervenção socioeducativo e intergeracional 'Entre Nós: os Livros', em 2017, 2018 e 2019, ou seja os livros, e a educação para a leitura, enquanto elementos de união de diferentes gerações.

\section{Objetivos e Metodologia: 'Entre Nós: os Livros' - uma estratégia de animação socioeducativa}

A metodologia do projeto 'Entre Nós: os Livros', assenta na investigação-ação que tem como objetivos responder a três grandes questões: 1) Os Programas universitários para a terceira idade, a decorrer em contexto de ensino superior, podem contribuir significativamente para uma mudança na forma como os jovens percecionam e constroem a imagem dos 'mais velhos'? 2) Podem as relações intergeracionais contínuas influenciar a perceção e as representações sociais que os jovens fazem dos 'mais velhos' e vice-versa? 3) Podem essas relações contínuas e consequentes representações sociais contribuir para uma melhor integração social dos 'mais velhos' na comunidade?

Para o efeito, decidimos propor o desenvolvimento de uma ação/projeto de animação socioeducativa e intervenção comunitária de média duração, de fevereiro a maio, a partir de um contexto de ensino superior, organizada numa 
dinâmica que permitisse que diferentes gerações estivessem numa interação contínua na construção e realização de um objetivo comum ${ }^{4}$.

O projeto tem como objetivo principal incentivar as relações intergeracionais a partir de um projeto socioeducativo, dinamizado por equipas socioeducativas intergeracionais.

Para o efeito, foi desenvolvida uma estratégia de ação, um projeto socioeducativo que promovesse as relações intergeracionais entre os dois grupos de estudantes (seniores e juniores). Procurou-se assim alimentar e justificar, de uma forma mais duradoura e efetiva, as interações contínuas entre ambos os grupos.

Para o subprojeto, a principal finalidade prendeu-se com a Promoção de uma Educação Literária, direcionada a diferentes públicos - creche, jardim-de-infância, 1.․o ciclo e a idosos institucionalizados (que viriam a ser os beneficiários diretos do subprojeto) -, constituindo-se como a principal estratégia potenciadora de uma interação intergeracional concreta ${ }^{5}$.

O projeto pressupõe a avaliação e recolha de informação, nomeadamente: avaliação da participação e do trabalho em equipa ao longo da ação/atividades (formação, preparação e intervenção) e a dinamização de Focus groups (Focus G) - Focus $G$ com os estudantes adultos 'mais velhos' do programa 'Escola de Educação Sénior', Focus G com os estudantes 'Juniores' e Focus G com os estudantes 'mais velhos' e 'Juniores', complementada com entrevistas individuais semiestruturadas.

A formação das equipas obedeceu a alguns critérios que asseguraram o equilíbrio entre os membros juniores e os 'mais velhos', garantindo a existência de um elemento mais velho em cada equipa.

Todos os participantes passaram por um processo de preparação e orientação que envolveu doze horas de formação - formação geral, específica e técnica, bem como de preparação dos produtos pedagógicos de intervenção que cada equipa iria produzir em função dos públicos específicos que deveriam servir. Participaram ainda em quatro palestras sobre literacia, literatura infantil e juvenil, contos tradicionais e técnicas de contar histórias.

4 "Projeto Intergeracional - Entre NÓS: os Livros": 2016-2018 - Conceção e operacionalização do projeto: Animadora socioeducativa estagiária: Teresa Silva e Orientador: António Leal (2017-2018) Continuidade do projeto: Animadora socioeducativa estagiária: Adriana Silva e Orientador: Virgílio Correia.

5 A ação foi pensada para ser realizada em duas fases: $1^{\text {a }}$ fase - Conceção da ação e operacionalizada, como prática de estágio curricular da licenciatura em ASE, tendo o seu início no ano letivo de 2016-2017 e continuação no ano letivo de 2017-2018, e $2^{\text {a }}$ fase - operacionalizada como programa de voluntariado e de intervenção intergeracional permanente da Escola Sénior e da Licenciatura em ASE, a iniciar a partir do ano letivo de 2018-2019. 
Em ambas as edições, o projeto culmina com a fase de intervenção, ou seja, a implementação no terreno das atividades pensadas e organizadas pelas dez equipas intergeracionais. Ao todo, as equipas realizaram vinte ações de intervenção, em nove instituições com diferentes valências: creche, jardim-de-infância, 1. ․ ciclo, centros de dia, Lar da Terceira Idade, no Museu Machado de Castro, e, ainda, no programa 'Coimbra a Brincar', promovido anualmente pela Associação de Paralisia Cerebral de Coimbra [APCC], em parceria com várias instituições educativas da cidade de Coimbra.

Participaram nestas duas fases 21 estudantes do Programa Escola de Educação Sénior de Coimbra, com idades compreendidas entre os 64 e os 78 anos de idade e 34 estudantes da licenciatura em Animação Socioeducativa com idades compreendidas entre os 18 e os 22 anos de idade, com uma média de dois estudantes 'mais velhos' e três estudantes juniores por equipa.

\section{Resultados: a Reconfiguração das Representações Sociais}

No âmbito do processo de recolha de dados associado à investigação-ação em curso, foram realizadas, em outubro de 2018 e 2019, quatro Focus Group, em que se propôs a cada grupo discutir vários temas no âmbito da juventude e da velhice: a imagem que tinham do 'outro', antes de virem para a ESEC, antes e após o projeto; as relações entre gerações; a importância que este projeto exerceu nas suas representações sociais sobre o 'outro' e no fomento de relações intergeracionais mais sólidas, duradouras e úteis a ambos os grupos sociais. Posteriormente foi solicitado a todos os elementos, que respondessem por escrito às mesmas questões colocadas durante os Focus Groups. Assim, para o presente trabalho, fazemos uso de algumas dessas informações recolhidas.

\subsection{Como os velhos veem os jovens}

As imagens veiculadas pelos estudantes do programa Escola de Educação Sénior sobre os jovens, após a participação no projeto 'Entre Nós: os Livros' é positiva, não se verificando alterações significativas relativamente às imagens que já possuíam inicialmente:

Se nós hoje aceitarmos os jovens com todas as suas diferenças, eles são uma juventude maravilhosa. Muito melhor do que no nosso tempo. Eles são muito mais enriquecidos culturalmente do que nós erámos (falo pelo menos da minha 
geração, da minha altura, quando tinha a idade que eles têm hoje quando entrei para aqui, para o magistério primário). (Maria de Jesus, 64 anos)6.

Penso que os seniores que participaram no projeto já tinham uma boa imagem a cerca dos jovens [...]. (Ana, 18 anos).

À luz das afirmações dos 'mais velhos', a ideia generalizada que se tem de que no passado [antigamente] as interações sociais entre os mais jovens e os 'mais velhos' eram mais normalizadas e profícuas, parece ser mais um mito do que realidade, aproximando-se mais de uma imagem bucólica do passado:

Tínhamos muito mais tendência ao grupinho, não deixando que os outros interviessem naquilo que nós pretendíamos. Não permitíamos que as gerações mais velhas interagissem connosco. Sempre houve e sempre haverá uma separação entre as gerações. Eramos muito mais fechados do que os jovens de hoje. Eles hoje [na ESEC] contactam connosco e aceitam a nossa intervenção dentro das próprias aulas deles. Por exemplo, antigamente, no magistério primário, os regentes que eram mais velhos tinham que tirar o curso aqui, e frequentar as aulas juntamente com jovens que estavam a tirar o curso de magistério. Nas minhas aulas havia jovens com quinze anos e adultos com 65 anos. Os alunos com quinze anos nunca conseguiram interagir com os grupos dos mais velhos, por falta de iniciativa dos mais velhos. Os mais novos sentiam-se retraídos e nada faziam para interagir com os mais velhos. Se na altura em nossas casas já eramos muito condicionados pelos nossos pais, que diziam o que poderíamos ou não fazer, 'fazes isso ou não fazes isso, porque eu quero! Logo essa relação com os mais velhos já era suficientemente inibidora da iniciativa dos mais jovens. Havia uma separação total. (Maria de Jesus, 64 anos).

De acordo com os entrevistados mais velhos, há uma maior abertura ao 'outro', fruto de um maior conhecimento que hoje em dia também já se tem do 'outro', graças não só a maior disponibilidade de informação, mas também de contactos e interações entre grupos de diferentes idades, culturas e classes sociais:

Hoje isso não se verifica. Hoje há um maior conhecimento, maior abertura. Concordo com o que a Ascenção disse. Ainda agora estive à hora do almoço a falar com um estudante de São Tomé. Eu não tive barreiras. Eu por ser mais velha não me inibi, nem ele se sentiu inibido por eu ser mais velha. Uma aceitação normal de ambas as partes. (Gabriela, 19 anos).

6 Os nomes dos testemunhos apresentados ao longo do texto são fictícios. Foram ainda omitidos todos os elementos que pudessem conduzir à identificação dos autores dos testemunhos. 
No entanto, não passa em branco o sentimento de indignação e reprovação relativamente a algumas atitudes e comportamentos dos mais jovens, como o dar o lugar a pessoas mais velhas nos transportes públicos, ou ainda, quando sentados num local de passagem, como uma escada, nada fazerem para facilitar e permitir o acesso a uma pessoa mais velha:

Verifica-se uma falta de respeito pelo outro, sobretudo no que respeita às regras de boa educação, como por exemplo segurar ou abrir uma porta para outra pessoa passar, ceder o lugar a outra pessoa mais velha ou com mais necessidade, cumprimentar as pessoas que já se conhece. Mas deve-se sobretudo à educação de base. (Emílio, 79 anos).

Este tipo de comportamento, quando vivido pelos próprios [mais velhos], é associado a um comportamento de desrespeito pelos 'mais velhos'. No entanto, a maioria dos participantes 'mais velhos' entrevistados não faz essa associação, justificando esse tipo de atitude e comportamento sobretudo com um desprendimento que alguns jovens apresentam relativamente às regras consensualmente consideradas de 'boa educação'. Esse tipo de comportamento não pode ser generalizada a todos os jovens, uma vez que na opinião dos 'mais velhos, estaremos mais perante uma situação de falta de educação de alguns jovens e não de todos, ou seja, um problema que tem a sua origem no seio da família de cada um e à falta de solidariedade para com o 'outro', independentemente da idade:

Parece haver uma falta de solidariedade para com os outros, mesmo que desconhecidos. (Artur, 68 anos).

A falta de emprego gera nos jovens uma maior competição entre eles e menos cooperação e solidariedade. (grupo 1, seniores).

\subsection{Como os Jovens veem os Velhos}

Já a imagem dos jovens sobre os mais velhos sofre alterações. Aqueles sendo detentores de novas informações em virtude da experiência vivida, constatam a existência de uma contradição com os atributos que até aí davam forma às representações existentes, ancoradas em estereótipos pré-existentes:

Eu acho que a minha mentalidade mudou um bocado desde que entrei para este curso. Eu já sabia que os idosos são pessoas limitadas [...] Quando vim para aqui e soube que havia uma escola Sénior, eu não sabia que muitos deles 
tinham conhecimentos e nada disso. Fomos capazes de aprender que afinal sabem mais do que nós sobre certos temas [...]. (Paula, 19 anos).

Não pensei que eles tivessem ainda tanta capacidade. Não sabia que ainda havia pessoas assim capazes de querer aprender mais. Durante o projeto eles eram bastante autónomos, muitos deles foram eles que se chegaram à frente com uma ideia e no dia seguinte já estavam a mandar mensagens com sugestões. Achei-os bastante participativos e autónomos e capazes de aprender e fazer... No início achava que eles estavam cá para aprender, mas que já não teriam tanta capacidade para aprender, para falar e debater, etc. (Paula, 19).

[...] na verdade nunca me tinha apercebido que existiam tantos idosos a querer aprender mais, a desenvolver projetos, a envolver-se com a comunidade escolar, o que para mim foi uma grande surpresa quando de repente, entro numa sala com imensos alunos da escola sénior sempre bem dispostos, e simpáticos, devo confessar que até me senti desconfortável logo de inicio pois via-os tão disponíveis, tão à vontade e eu ali envergonhada sem saber bem no que me estava a 'meter'. Tive imensa curiosidade em os conhecer, eu e as minhas colegas, penso que aqui posso falar por quase todas. (Maria Santos, 19 anos).

Antes de vir para aqui, não sabia que havia idosos que queriam aprender como acontece aqui. Não sabia que existiam 'idosos jovens', isto é com espírito jovem. (Júlia, 19 anos).

Estas novas informações, recolhidas em primeira mão, permitem que estes façam uma seleção de novos elementos - atributos, elaborando novos conteúdos que objetivamente contribuirão para a definição de novas formas, de novas imagens sobre a realidade que agora lhes é familiar. Ao partilhar mentalmente essa realidade, fazem uso de novas representações sociais sobre os 'mais velhos', muito mais positivas:

Há idosos que têm um estado de espirito jovem: são ativos, com iniciativa, criativos, dinâmicos, com um envelhecimento bem-sucedido [fisicamente e intelectualmente], interativo. (Grupo 1, Jovens).

Se calhar no início do projeto tínhamos a ideia de que eramos todos diferentes. Mas com o desenvolver do projeto já eramos todos iguais, trabalhávamos de igual modo, fazíamos as mesmas coisas... No início pensávamos que se calhar eles não tinham a mesma capacidade que nós para fazer as coisas, que nós é que iriamos ter que fazer tudo e eles não vão conseguir acompanhar-nos. Mas afinal eles conseguiram fazer tudo, e até se calhar melhor do que nós... Acho que se agarram mais ao projeto do que nós... Como nós pensávamos que os idosos são uma população vulnerável, que não iam conseguir fazer as coisas como nós, não sei, que não iam conseguir. (Salomé, 20 anos). 
Pensava que no projeto nós é que tínhamos de fazer tudo, e que eles não iam ter um papel tão participante como tiveram. (Gracinda, 19 anos).

Os seniores mostraram-se pessoas queridas, disponíveis, comunicativas, alguns determinados..., inteligentes, criativos e realistas. Estas foram as características que identifiquei nos primeiros contactos que tive com eles. Uma imagem que constatei nos seniores foi o facto de compreenderem, protegerem e defenderem as ideias e opiniões de nós jovens quando assim se justificava [...] (Marta L, 22 anos).

Também para os mais novos, são inúmeros os benefícios, aumentando a sua resistência, capacidade empática, relacionamentos sociais e melhora a sua perceção sobre o envelhecimento. Para mim acho significativo a existência destas relações intergeracionais, pois ambas as gerações possuem saberes e a sua troca possibilita vivenciar vários modos de pensar, de agir e de sentir, assim como mudar opiniões e visões a respeito do mundo e das pessoas, respeitando as suas diferenças e podendo assim criar uma história comum, a partir das sabedorias de cada um. (Marta L., 22 anos).

A existência de cooperação entre gerações é o melhor caminho para uma sociedade equilibrada, pois na minha cabeça já não existe aquela ideia de que quando for velha não vou parar de realizar sonhos ou objetivos que poderão ser diferentes neste momento da minha vida, mas que irão mudar e serão outro tipo de metas e objetivos. (Ana, 18 anos).

Como é possível constatar pelas transcrições apresentadas, a experiência de interação social com adultos 'mais velhos' vivenciada por estes jovens são reveladoras de três factos significativos: 1) eram inicialmente detentores de representações sociais sobre os velhos e a velhice ancoradas em estereótipos sociais de debilidade física e cognitiva, fraqueza, inatividade, inutilidade, etc.; 2) a entrada numa licenciatura na ESEC e o conhecimento da existência de um programa de educação para adultos 'mais velhos' - seniores é suficientemente significativo para começarem a questionar as representações sociais anteriores sobre os velhos; 3 ) e que as estratégias de animação socioeducativa de grande impacto e promotoras das relações intergeracionais são suficientes para provocar a reconfiguração das representações sociais e o combate aos estereótipos sociais, permitindo a valorização dos saberes e das experiências dos mais velhos, aumentando a coesão social e consequentemente contribuem para uma maior e melhor integração destes na comunidade. 
Neste trabalho procurámos, através do relato de uma experiência, demonstrar que a existência de relações sociais significativas e facilitadoras da descoberta do 'outro' - do encontro e da partilha de interesses, de objetivos e propósitos comuns - que permitam colocar ambos os grupos geracionais em interação num mesmo patamar do saber, do saber fazer e do fazer, são geradoras não só de novas representações socias, mas também das disposições de ação, ou seja, do modo como passam a interagir com o público mais velho, o que tudo indica que as nossas suposições iniciais se verificam. Um dos grandes benefícios deste tipo de intervenção é permitir, no mínimo, que estes jovens, futuros profissionais socioeducativos, que trabalharão porventura com públicos adultos 'mais velhos' em diferentes contextos institucionais, percebam que a velhice não pode ser categorizada socialmente apenas em função da idade cronológica, que não existe apenas uma categoria social 'velhos', com características homogéneas, mas existem diferentes perfis de 'velhos', em função das suas caraterísticas biológicas e ambientais, dos seus trajetos de vida e condição social (MAURITTI, 2004). As suas diferenças pressupõem necessidades, interesses e aspirações também diferentes, bem como exigem formas de intervenção diferenciadas:

Ao contrário do que referi antes, aprendi que o envelhecimento tem de ser contrariado com este tipo de projetos imprescindíveis, visto que quanto mais ativo for o idoso no passado mais possibilidades tem de continuar ativo na idade mais avançada e investindo em diversas áreas a nível da sociedade, família, trabalho e lazer, envelhecendo de uma forma mais saudável conservando as suas funções cognitivas. (Marta L., 22 anos).

Acredito que o facto de existirem relações de trabalho contínuas entre as diferentes gerações foi importante na medida em que nos aproximou, a nós jovens dos seniores e vice-versa, creio que o facto de o trabalho ter sido desenvolvido de forma continua e com diversas ações de formação fez com que nos mantivéssemos sempre unidos enquanto grupo coeso e convicto de que no fim tudo iria correr bem daí achar importante o trabalho ser desenvolvido de forma continua. (Maria S., 19 anos).

Hoje posso contar sempre com um sorriso, um cumprimento, ou algumas palavras de seniores como a dona Ascensão, o senhor José, o senhor Alfredo, a dona Emília, a Ju, o senhor lídio, a Márcia, a Gabriela, a Rosa e o António. (Maria S., 19 anos). 
Por outro lado, este tipo de intervenção poderá igualmente ter impactos positivos na autoimagem que os mais velhos produzem de si, bem como promover na comunidade de referência a inclusão de novos elementos nas representações sociais que esta produz e transmite dos seus cidadãos mais velhos, permitindo a sua valorização, o reconhecimento de papéis sociais de significativa importância para as suas comunidades, aumentando a cooperação entre diferentes gerações e a coesão social, mas sobretudo permite a perceção dos mais velhos como recursos de grande valor, ou seja, como capital de grande valor e utilidade a ser mobilizado para o desenvolvimento da comunidade.

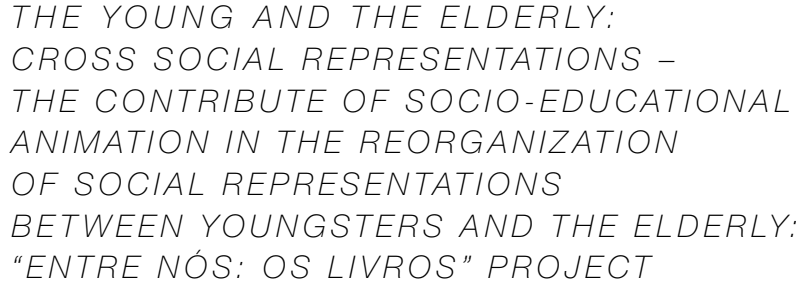

\section{abstract}

Young people describe the elderly and old age itself with negative attributes and traits, linking this period of life with a number of physical, cognitive and social losses. However, the elderly don't represent themselves negatively at all.

On the other hand, the elderly describe young people with very positive attributes and traits, especially related to the inherent liveliness of this particular stage of life. Yet they add some negative traits, mostly related to certain behavioural aspects.

The role of socio-educational animation is to declare the elderly able to participate and intervene in community life. It focuses mainly on the participation processes that encourage social and cultural development processes. The intergenerational participation is undoubtedly the main pillar of this process, from which one can define the practices of socio-cultural animation.

In this article, we will try to answer some of the questions that will help us understand how continuous intergenerational relationships may influence the perception and social representations made by the youngsters and the elderly about each other.

This work is based on preliminary data collected in the scope of an ongoing action research, as such, its remarks can't be deemed as conclusive. 
Old Age. Social Representations. Intergenerationality. Social Interactions. Socio-educational Animation.

referências

ALMEIDA, Mariana. Envelhecimento: Activo? Bem-sucedido? SAUDÁVEL? POSSIVEIS COORDENADAS DE ANÁLISE. Revista Fórum Sociológico, n. 17, p. 17-24, 2007. [II série]

ANÍBAL, Alexandra. Da educação permanente à aprendizagem ao longo da vida e à Validação das aprendizagens informais e não formais: recomendações e práticas. CIES e-Working Paper, n. 147/2013. Lisboa: CIES-IUL, 2013.

BEAUVOIR, Simone. A velhice: a realidade incomoda. São Paulo: Difusão Europeia do Livro, 1990.

DEBERT, Guita. A Reinvenção da Velhice: socialização e processos de reprivatização do envelhecimento. São Paulo: Editora da Universidade de São Paulo, 2004.

FRIES, James. Medical perspectives on successful ageing. In: BALTES, Paul B;; BALTES, Margret M. (eds.). Successful ageing. Cambridge, UK: Cambridge University Press, 1990

HADDAD, Eneida. A ideologia da velhice. São Paulo: Cortez, 1986.

JODELET, Denise. Social representations: the beautiful invention. Journal for de theory of social behavior. v. 38, n. 4, p. 411-430, 2008.

JODELET, Denise. La representación social: Fenómenos, concepto y teoría. In: MOSCOVICl, Serge (org.). Psicología social. Barcelona: Paidós, vol. 2, p. 469-494, 1993.

LEAL, António. Educação Intergeracional e Desenvolvimento Comunitário. In: F. SOUSA; D. PEREIRA; M. LOPES (orgs.). Animação Sociocultural, Território Rural, Património, Turismo, Envelhecimento e Desenvolvimento Comunitário: Estratégias, Recursos e Métodos de Combate ao Despovoamento. Chaves: Intervenção, p. 51-56, 2019.

LEAL, António. Gerontologia Educativa e Animação Socioeducativa na Terceira Idade: o Projecto IHSénior. Dissertação (Mestrado em Gerontologia Educativa e Animação Socioeducativa). Instituto Politécnico de Coimbra. Coimbra, 2015.

LOPES, Marcelino. Animação sociocultural e gerontologia: bases para uma intervenção social, cultural e educativa. In: PEREIRA, José Dantas Lima; LOPES, Marcelino de Sousa; RODRIGUES, Tânia Monteiro (orgs.). Animação sociocultural. Gerontologia e Geriatria. A Intervenção Social, Cultural e Educativa na Terceira Idade. Chaves: Intervenção, p. 211-222, 2013.

MARTINS, Rosa; RODRIGUES, Maria. Estereótipos sobre idosos: uma representação social gerontofóbica. Millenium. Revista do ISPV, v. 29, p. 249-254, 2004.

MAURITTI, Rosário. Padrões de vida na velhice. Análise social. Vol. XXXIX, n. 171, p. 339-363. 2004.

MOSCOVICl, Serge. A representação social da psicanálise. Rio de Janeiro: Zahar, 1981.

OLIVEIRA, Flávia; OLIVEIRA, Rita. O ensinar e o aprender com a terceira idade. Lisboa: RUTIS. 2002.

PAÚL, Constança. Envelhecimento activo e redes de suporte social. In: Sociologia. Revista da Faculdade de Letras do Porto, v. XV, p. 275-288, 2005. 
SALGADO, Lucília; LEAL, António. Educação de Adultos Idosos: uma mais-valia na sociedade do conhecimento. In: PEREIRA, José Dantas Lima; LOPES, Marcelino de Sousa; RODRIGUES, Tânia M. Moreira (orgs.). Animação sociocultural. Gerontologia e Educação Intergeracional. Chaves: Intervenção, p. 97-108, 2015.

SANTOS, Verônica; TURA, Luiz; ARRUDA, Angela. As Representações Sociais de pessoa velha construídas por adolescentes. In: Revista Brasileira Geriatria Gerontologia. Rio de Janeiro, v. 14, n. 3, p. 497-509, 2011

SILVA, Aurora. Representações sociais na Velhice. Dissertação (Doutoramento em Psicologia). Faculdade Psicologia. Universidade do Porto. Porto, 2011

SILVA, Maria. "Se fosse tudo bem, a velhice era boa de enfrentar!" Racionalidades leigas sobre envelhecimento e velhice - um estudo no Norte de Portugal. Dissertação (Doutoramento em Sociologia). Universidade Aberta. Lisboa, 2006.

VALA, Jorge. As representações sociais no quadro dos paradigmas e metáforas da psicologia social. Análise Social, v. 28, p. 887-919, 1993

VALA, Jorge. Representações sociais e psicologia social do conhecimento cotidiano. In: VALA, Jorge; MONTEIRO, Maria Benedicta (orgs.). Psicologia social. Lisboa: Fundação Calouste Gulbenkian, p. 457-502, 2000.

VELOSO, Esmeraldina. As Universidades da Terceira Idade em Portugal: contributos para a análise da sua emergência. Revista Portuguesa de Pedagogia, p. 41-42, p. 233-257, 2007.

Data de Submissão: 04/04/2020

Data de Aprovação: 26/06/2020 